\title{
Effects of Potassium Dichromate on Distribution of Toxocara canis Larvae within Brain of Mice
}

\author{
Ayoub Abdulwahid Bazzaz ${ }^{1}$, Neama Ali Ahmad ${ }^{1}$ and Noorhan Ali Chelebi ${ }^{2}$ \\ 1. Department of Biology, Faculty of Sciences, University of Kirkuk, Kirkuk, Iraq \\ 2. Department of Chemistry, Faculty of Sciences, University of Kirkuk, Kirkuk, Iraq
}

\begin{abstract}
The frequency of the infective larvae of Toxocara canis, the common parasite of the dog was assessed in brain portions of male Albino mice ingested two doses: $200 \mathrm{mg} / \mathrm{Kg}$ and $400 \mathrm{mg} / \mathrm{Kg}$ of potassium dichromate-hexavalent (VI) as an indicator. Only 2,000 ova of the parasite were inoculated orally to twenty seven healthy young male mice. Frequency of the parasite was tested 13 weeks post-inoculation. Using bio-statistical analysis (one way analysis of variance) the frequency of detected larvae of both doses in the brain portions of the experimental animals showed an insignificant difference $(p \geq 0.05)$ in comparison with control. The results indicate the safety of small and mild intoxication doses of the potassium dichromate on distribution of Toxocara canis in brain portions of mice.
\end{abstract}

Key words: Potassium dichromate, Toxocara canis, brain, immunity.

\section{Introduction}

The interest in the biochemical and toxicological aspects of chromium is due to its role as environmental pollutants and a nutritional factor in the public as well as a suspected carcinogenic in occupationally exposed workers [1]. Potassium dichromate, $\mathrm{K}_{2} \mathrm{Cr}_{2} \mathrm{O}_{7}$, a crystalline ionic solid with a very bright, red-orange color, is a common inorganic chemical reagent, most commonly used as an oxidizing agentin various laboratory and industrial applications. As with all hexavalent chromiumcompounds $\mathrm{Cr}(\mathrm{VI})$, it is acutely and chronically harmful to health. The salt is popular in the laboratory because it is not deliquescent, in contrast to the more industrially relevant salt sodium dichromate [2]. The exposure sources of chromium compounds are described in some other works [3-5]. The main use of $\mathrm{Cr}(\mathrm{VI})$ is as a precursor to potassium chrome alum, used in leather tanning [2-6].

Side effects of it may extend further to other

Corresponding author: Ayoub Abdulwahid Bazzaz, Ph.D., professor, main research field: effects of chemicals on animal tissues. E-mail: ayoubbazzaz@yahoo.co.uk. industries. In 2005-2006, potassium dichromate was the 11 th-most-prevalent allergenin patch tests $(4.8 \%)$ [7] and one of the most common causes of chromium dermatitis [8]. It is highly likely to induce sensitization leading to dermatitis, especially of the hand and fore-arms, which is chronic and difficult to treat. Toxicological studies have further illustrated its highly toxic nature. With rabbits and rodents, concentrations as low as $14 \mathrm{mg} / \mathrm{Kg}$ have shown a 50\% fatality rate amongst test groups [9]. Aquatic organisms are especially vulnerable if exposed; hence responsible disposal according local environmental regulations is advised. As with other $\mathrm{Cr}(\mathrm{VI})$ compounds, is carcinogenic and should be handled with gloves and appropriate health and safety protection. It also is corrosiveand exposure may produce severe eye damage or blindness [10]. Human exposure further encompasses impaired fertility, heritable genetic damage and harm to unborn children.

In a previous work the toxic effects of potassium dichromate was assessed on various tissues of mice [5] and the toxicity of the lead monoxide on the activity of immune system in fighting the infectious larvae of Toxocara canis was assessed [11]. The distribution 
frequency of Toxocara canis larvae was significantly higher in mice fed on lead monoxide indicating the toxicity of lead monoxide. This led us to explore whether the ingestion of potassium dichromate does exert any similar inhibiting effects on immune system as the lead monoxide.

The parasite Toxocara canis has a complex ascarid life cycle as it is not immediately infectious when it leaves the definitive host. It must grow and develop into the infective stage, ensheathed, in order to infect the definitive host. When Toxpcara canis ova are intubated to mice (the normal host), the larvae hatches and invades the wall of small intestine within 2 hours [12]. After one day, they accumulate in the liver, lungs, kidneys and spleen. They may eventually invade the brain and the eyes $[13,14]$. They may cause ocular lesions [15] and an epileptic condition in man. Their survival in the brain is interpreted to be as refuge free from the effects of host immunological responses [14]. A $2.5 \%$ solution of potassium dichromate at $4{ }^{\circ} \mathrm{C}$ could provide an infectivity of Cryptosporidium oocytes for immune suppressed adult mice [16]. In the present work, ingestion of potassium dichromate crystals, similarly to lead monoxide, wastested against the distribution of Toxocara canis larvae in brain portions.

\section{Materials and Methods}

Extraction of the Toxocara canis egg from the intestine of dead puppies was performed according to method described by Al-Tae [11]. Twenty seven healthy newly weaned male mice were selected to study the distribution frequency of the infective larvae in brain portion. All animals were divided into groups and maintained under identical environmental condition at $25{ }^{\circ} \mathrm{C} \pm 2$. Normal laboratory chow and tap water were available $a d l i b$ and were replaced three times a week. Using gavage animals were intubated with 2,000 eggs of the parasite.

Potassium dichromate crystals were obtained from FLUKA AG, CH-9470 Buschs, Switzerl and as ground powder and mixed with diet to prepare two concentrations (doses) of 200 and $400 \mathrm{mg} / \mathrm{Kg}$ body weight. The mice were fed the mixture for 13 weeks as $200 \mathrm{mg} / \mathrm{Kg}$ body weight $(\mathrm{G} 1=8)$ or $400 \mathrm{mg} / \mathrm{Kg}$ $(\mathrm{G} 2=10)$. After 13 weeks, all animals were sacrificed by cervical head dislocation for Toxocara canis distribution test. The brain was dissected out and cut into 4 pieces; the two cerebral hemispheres, and left and right ( $\mathrm{LCH} \& \mathrm{RCH}$ ); medulla oblongata (MO); and cerebellum. They were then squashed between two clean and dried slides and counting of the larvae was done by direct examination via Olympus BO light microscopy.

\section{Results}

Upon continuous monitoring system, neither epilepsy-like condition nor any other abnormal behavioral condition was recorded. However, via counting the frequency of the migrant larvae to the brain portions, insignificant differences $(p \geq 0.05)$ were seen between group 1 (G1) and (G2) in comparison with control (Table 1).

\section{Discussion}

The resulting pathology of Toxocara canis is

Table 1 The frequency of Toxocara canis larvae in brain portions of mice ingested with $200 \mathrm{and} 400 \mathrm{mg} / \mathrm{Kg} \mathrm{b}$. wt. potassium dichromate for 13 weeks, respectively. MO, medulla oblongata; LCH and $\mathrm{RCH}$, left \& right cerebral hemisphere; $p$, (student-T test).

\begin{tabular}{llllll}
\hline \multirow{2}{*}{ Animal groups } & \multicolumn{5}{c}{ Mean density of Toxocara canis larvae in brain portions } \\
\cline { 2 - 5 } & MO & LCH & RCH & Cerebellum & Total \\
\hline Control $(\mathrm{n}=9)$ & $6.9 \pm 2.1$ & $30.3 \pm 4.3$ & $28.7 \pm 2.19$ & $23.5 \pm 2.9$ & $89.4 \pm 7.4$ \\
Group-1 $(\mathrm{n}=8)$ & $8.5 \pm 2.1$ & $29.9 \pm 3.3$ & $27.0 \pm 2.4$ & $23.6 \pm 3.1$ & $89.0 \pm 4.7$ \\
$p$ & $>0.05$ & $>0.05$ & $>0.05$ & $>0.05$ & $>0.05$ \\
Group-2 $(\mathrm{n}=10)$ & $11.0 \pm 1.3$ & $24.3 \pm 2.8$ & $25.1 \pm 1.9$ & $25.3 \pm 2.3$ & $83.5 \pm 4.8$ \\
$p$ & $>0.05$ & $>0.05$ & $>0.05$ & $>0.05$ & $>0.05$ \\
\hline
\end{tabular}


dependent on the intensity of infection and the location of the larvae within the body organs [17]. Infection protocols or mice strains also vary considerably making species comparison difficult [18]. It also suggested that Toxocara canis larval burdens vary between individual out bred mice receiving the same inoculation may refer to the role of immunity in the establishment of irreversible brain, particularly, cerebral infection [19]. The mice strain used in this study might have been different; and hence interprets the lower concentration of control mice in the present results than those of other studies [11, 15, 20]. Nevertheless, mice remain a useful animal model for significant applicability and manipulation.

With lead monoxide used instead of potassium dichromate, ingestion Toxocara canis ova, produced almost 3-4 folds (significant differences $(\mathrm{p} \leq 0.05)$ ) frequency of the infective larvae in brain portions of mice more than in the present results [11]. The lower density of the infective larvae with potassium dichromate could be interpreted as the effect of the $\mathrm{Cr}(\mathrm{VI})$ was less toxicity exerted on the immune system in comparison with lead monoxide. These results are concomitant with those of Abdelhameed [20] and the most recent work of Holland and Hamilton [19] in that the greater concentration of the parasites in the brain could result as infection progress.

The results indicates that future systematic immune responses to Toxocara canis in the brain has received little attention so far which open the door wide for future immunological researches to link the distribution of the infective larvae to the immune system in both human and animal.

\section{Conclusion}

Perhaps potassium dichromate is much safer than lead monoxide in affecting immune system in mice. Animal species, strains and inoculation methods may yield varying results dependent on susceptibility of each and perhaps to environmental condition too.
Further experiments are necessary to link the distribution of Toxocara canis larvae with the immunological studies would help in understanding the implication of various heavy metals as well as cerebral toxocariasis.

\section{Acknowledgement}

Thanks are due to Mrs Suhair Abdulkadir, the veterinary doctor for her technical help in caring of the animals during the course of this research.

\section{References}

[1] Edel, J., and Sabbioni, E. 1985. "Pathways of Cr(III) and $\mathrm{Cr}(\mathrm{VI})$ in the Rat after Intra-tracheal Administration." Hum Toxicol 4 (4): 409-416.

[2] Anger, G., Halstenberg, J., Hochgeschwender, K., Scherhag, C., Korallus, U., Knopf, H., Schmidt, P., and Ohlinger, M. 2005. Chromium Compounds in Ullmann's Encyclopedia of Industrial Chemistry. Weinheim: Wiley-VCH.

[3] Stern, R. M. 1982. Chromium Compounds; Production and Occupational Exposure. In: Langard, S., Ed. Biological and Environmental Aspects of Chromium. Amsterdam: Elsevier Biomedical Press.

[4] E. Sabbioni, E., Goetz, L., and Bignoli, G. 1984. "Health and Environmental Implications of Trace Metals Released from Coal-fired Power Plants: An Assessment Study of the Situation in the European." Com. Sci. Total University 40: 141-154.

[5] Bazzaz, A. A., Sulaiman, N. M., and Muhsin, S. S. 1989. Histopathological and Hematological Effects of Potassium Dichromates on Mice. In 5th Sci. Conf. SRC Proceeding: 297-310.

[6] Saha, M., Srinivas, C. R., Shenoy, S. D., and Balachandran, C. 1993. "Footwear Dermatitis." Contact Dermatitis 28 (5): 260-264.

[7] Zug, K. A., Warshaw, E. M., Fowler, J. F., Maibach, H. I., Belsito, D. L., and M. D. Pratt, et al. 2009. "Patch-test Results of the North American Contact Dermatitis Group 2005-2006." Dermatitis 20 (3): 149-60.

[8] Master, F. J. 2003. Diseases of Skin. New Delhi: B. Jain Pub. Pvt. Ltd..

[9] Bock, R. 1972. Aufschlussmethoden Der Anorg. and Org. Sigma-Aldrich: Potassium Dichromate MSDS.

[10] Baker, J. T. 1996. Potassium Dichromate MSDS. Sigma-Aldrich: Potassium Dichromate MSDS.

[11] Al-Tae, A. R., Bazzaz, A. A., Bashir, N. M., and Sulaiman, N. M. 1988. "The Combined Effects of Lead Monoxide and Toxocara canis Infective Larvae on the CNS of Mice.” J. Biol. Sci. Res. 19 (3): 647-658. 
[12] Al-Zubaidi, B. A. 1980. "Studies on the Biology of the Ascarid Parasites of Dogs and Cats." Ph.D. thesis, University College of Bangor, North Wales, UK.

[13] Ho, T. T., Tury, E., and Kobulej, T. A. 1974. "Toxocara canis Larva Okostaszovetielvaltozasokeğerben." Parasitologica Hungarica 7: 69-84.

[14] Dunsmore, J. D., and Thompson, R. C. A. 1983. "The Accumulation of Toxocara canis Larvae in the Brains of Mice.” Inter. J. Parasitology 13: 517-521.

[15] Yang, S., Healy, M. C., and Du, C. 1996. "Infectivity of Preserved Cryptosporidium Parvum Oocyte for Immunosuppressed Adult Mice." FEMS Immunology \& Medical Microbiology 13: 141-145.

[16] Ashton, N. 1960. "Larvalgranulo-matosis of the Retina Due to Toxocara." British J. Opthal. 44: 129-148.
[17] Smith, H. V. 1991. Immune Evasion and Immunopathology in Toxocara canis Infection. In Parasitic Nematods-antigen, Membrane and Genes (ed. M. W. Kennedy). London: Taylor and Francis.

[18] Holland, C. V. and Smith, H. V. 2006. Toxocara the Enigmatic Parasite. Wallingford, Oxfordshire, UK: CABI Publishing.

[19] Holland, C. V., and Hamilton, C. M. 2014. "The Significance of Cerebral Toxocariasis: A Model System for Exploring the Link between Brain Involvement, Behavior and Immune Response.” J. Exp. Biology 216: 78-83.

[20] Abdel-Hameed, A. A. 1984. "Effect of Thiabendazole on the Migration of Toxocara canis Larvae in the Mouse." J. Parasitology 70 (2): 226-231. 